Journal of

Low Power Electronics and Applications

ISSN 2079-9268

www.mdpi.com/journal/jlpea/

Correction

\title{
Heavy Ion Characterization of a Radiation Hardened Flip-Flop Optimized for Subthreshold Operation. J. Low Power Electron. Appl. 2012, 2, 168-179
}

\section{Ameet Chavan ${ }^{1}$, Praveen Palakurthi ${ }^{1}$, Eric MacDonald ${ }^{1, *}$, Joseph Neff ${ }^{2}$ and Eric Bozeman $^{2}$}

1 University of Texas at El Paso, Electrical and Computer Engineering, El Paso, TX 79968, USA;

E-Mails: aochavan@utep.edu (A.C); pkpalakurthi@miners.utep.edu (P.P.)

2 SPAWAR System Center, Navy, San Diego, CA 92152, USA;

E-Mails: jdneff@spawar.navy.mil (J.N.); eric.bozeman@navy.mil (E.B.)

* Author to whom correspondence should be addressed; E-Mail: emac@utep.edu;

Tel.: +915-747-6959; Fax: +915-747-7871.

Received: 25 September 2012 / Published: 26 September 2012

We have found the following error in the title of this article which was recently published in J. Low Power Electron. Appl. [1]:

The correct title should be: Heavy Ion Characterization of a Radiation Hardened Flip-Flop Optimized for Subthreshold Operation.

We apologize for any inconvenience caused to the readers.

\section{References}

1. Chavan, A.; Palakurthi, P.; MacDonald, E.; Neff, J.; Bozeman, E. Hardened Flip-Flop Optimized for Subthreshold Operation Heavy Ion Characterization of a Radiation. J. Low Power Electron. Appl. 2012, 2, 168-179.

(C) 2012 by the authors; licensee MDPI, Basel, Switzerland. This article is an open access article distributed under the terms and conditions of the Creative Commons Attribution license (http://creativecommons.org/licenses/by/3.0/). 